\title{
Study on Polymer Materials for Development of the Super 100 MGy-Radiation Resistant Motor
}

\author{
Yasuhiko ONISHI, ${ }^{\dagger, \dagger}$ Tetsuya SHIGA, ${ }^{1}$ Yoshinao OHKAwA, ${ }^{2}$ Haruzou KATOH, ${ }^{3}$ \\ Kiyoshi Nagasawa, ${ }^{4}$ Tsuneyoshi OKadA, ${ }^{5}$ Kenji SaImen, ${ }^{6}$ Fumihiro Itano, ${ }^{7}$ \\ Yoshihiro Murano, ${ }^{8}$ Yoshiharu TsujITA, ${ }^{9}$ Toshiaki YAGI, ${ }^{10}$ \\ Yousuke Morita, ${ }^{10}$ and Tadao SEGUCHI ${ }^{10}$ \\ Nippon Bunri University, Oita 870-0397, Japan \\ ${ }^{1}$ Sumitomo Wiring Systems Ltd., Suzuka 513-8631, Japan \\ ${ }^{2}$ JAERI Naka, Naka 311-0102, Japan \\ ${ }^{3}$ Toyo Aluminum K.K., Chuo-ku, Osaka 541-0056, Japan \\ ${ }^{4}$ Meidensha Corporation, Nishi-biwajima-cho, Aichi 452-8602, Japan \\ ${ }^{5}$ Polyplastics Co., Ltd., Minato-ku, Tokyo 108-8280, Japan \\ ${ }^{6}$ Kuraray Co., Ltd., Kita-ku, Osaka 530-8611, Japan \\ ${ }^{7}$ Nippon Oil Corporation, Minato-ku, Tokyo 105-8412, Japan \\ ${ }^{8}$ Kandenko Co., Ltd., Minato-ku, Tokyo 108-0014, Japan \\ ${ }^{9}$ Nagoya Institute of Technology, Nagoya 466-8555, Japan \\ ${ }^{10}$ JAERI Takasaki, Takasaki 370-1207, Japan
}

(Received March 1, 2004; Accepted March 10, 2004; Published August 15, 2004)

\begin{abstract}
A super radiation-resistant motor was developed for a project of ITER, in which the insulation materials consist of high radiation-durable organic materials such as poly(benz-imidazole) (PBI), poly(arylate) $\left(\right.$ VECRUS $^{\circledR}$, VECTRA $^{\circledR}$ ), and poly(phenyl-ether/urea) grease. The motor was tested by $\gamma$-rays irradiation for 2 years under power supply, and confirmed to have high radiation resistance over $100 \mathrm{MGy}$, which is 50 times higher than an ordinary radiation durable motor for a nuclear power station. The key technology was the selection of radiation resistant polymers and further improvement of radiation resistance by mixing aluminum (Al) micro-flakes in organic polymers. The effects of $\mathrm{Al}$ flake to prevent radiation degradation of polymer were assumed to be channeling of secondary electron induced by $\gamma$-ray irradiation. [DOI 10.1295/polymj.36.617]

KEY WORDS Motor / Radiation Resistance / 100 MGy / Poly(benz-imidazole) (PBI) / Poly(arylate) $\left(\right.$ VECRUS $^{\circledR}$, VECTRA $\left.^{\circledR}\right)$ / Al Flake / ITER /
\end{abstract}

Electric equipment and components applied in a nuclear power station should be requested to have radiation resistance of $2 \mathrm{MGy} .{ }^{1}$ Because, the organic insulation materials used in the equipment and components are degraded by ionizing chemical reactions in radiation environment. In the project of International Thermonuclear Fusion Experimental Reactor (ITER), $100 \mathrm{MGy}$ radiation resistance of electric equipments is required. It is 50 times higher than nuclear power plants. A motor is the most important component in the robotic machines used for inspection and maintenance of the interior walls of a reactor. The radiation level inside the reactor at maintenance is estimated to be $10-100 \mathrm{kGy} / \mathrm{h}$ at $100-200^{\circ} \mathrm{C}$, and the major radiation is $\gamma$-ray. Radiation durability of the motor must be $100 \mathrm{MGy}$ to $\gamma$-ray exposure. In the works by Japan (Japan Atomic Energy Research Institute: JAERI), a high radiation resistant motor was developed with the research works of equipment and components. ${ }^{2}$ A number of research groups in- cluding private companies participated in the project.

The key component for the high radiation resistance motor is insulation material of organic polymers. ${ }^{3}$ The first stage of this project was selection of polymers with high radiation resistance. Evaluation of radiation resistance was carried out by $\gamma$-ray irradiation and high energy electron beam irradiation. In the second stage, the radiation resistance of selected polymers was improved using various additives. Toyo Aluminum K.K. succeeded in blending aluminum ( $\mathrm{Al}$ ) micro-flakes (fine film leaves) into aromatic polymers, and new formulated polymers were found very effective for reduction of polymer degradation by radiation exposure. This technique was applied to other polymers such as lubricant, and the radiation resistance of each component for motor insulation was improved and a high radiation-resistant motor attaining a level of $100 \mathrm{MGy}$ was produced. This paper describes the development of component materials for high radiation-resistant insulation and characteristics.

\footnotetext{
${ }^{\dagger}$ To whom correspondence should be addressed (E-mail: VYX00545@nifty.ne.jp).

${ }^{\dagger \dagger}$ Present address: Sumitomo Wiring Systems Ltd., Suzuka 513-8631, Japan
} 


\section{MATERIAL EVALUATION AND SELECTION}

Radiation resistance of polymer materials was evaluated by the decay of properties such as mechanical and electrical properties after $\gamma$-rays irradiation. Through chemical reactions induced by irradiation, polymer chains break or make new bonds between chains and the properties as polymer material degrade with increase in irradiation. The radiation resistance depends on chemical structure, and polymers containing aromatics have high resistance to radiation degradation. Therefore, recently developed aromatic polymers were selected and the radiation resistance was tested by ${ }^{60} \mathrm{Co} \gamma$-rays irradiation at $250{ }^{\circ} \mathrm{C}$ in inert gas atmosphere at $20 \mathrm{kGy} / \mathrm{h}$ and by $2 \mathrm{MeV}$ electron beam irradiation at ambient temperature in air or in inert gas atmosphere with a dose rate $5-10 \mathrm{kGy} / \mathrm{s}$. Irradiation effects by electron beam to polymers are fundamentally the same as $\gamma$-ray irradiation, but the $2 \mathrm{MeV}$ electron beam penetration into polymer material is limited to $6 \mathrm{~mm}$ thick, and polymer samples are heated during irradiation when the dose rate is 5$10 \mathrm{kGy} / \mathrm{s}$. However, in the case of electron beam irradiation, the irradiation period can be shortened by thousand times compared with $\gamma$-ray irradiation. Therefore, electron beam irradiation was used for the evaluation of thin films or fibers of aromatic polymers.

The selected organic polymers, which have high radiation resistance of $100 \mathrm{MGy}$ level, were (A) poly(benz-imidazole) (PBI) for a varnish of coil wire, (B) poly(arylate) $\left(\right.$ VECRUS $^{\circledR}$, VECTRA $^{\circledR}$ ) for insulation spacer, and (C) poly(phenyl-ether) for lubricant which is a grease mixed with urea and poly(phenyl-ether). B and $\mathrm{C}$ are modified using Aluminum micro-flakes to improve radiation resistance. Properties and radiation resistance of the polymer materials are as follows.

\section{Poly(benz-imidazole) (PBI)}

PBI is applied to a varnish material for coil wires, because PBI has high insulation potential, superior heat resistance, high tensile strength and high flexural modulus. PBI coated cupper coil $(\mathrm{Cu} / \mathrm{PBI}$ coil: diameter $0.55 \mathrm{~mm}$, coating thickness $20 \mu \mathrm{m}$ ) withstands a voltage $4.8 \mathrm{kV}$ by Japanese Industrial Standard (JIS) C3210. ${ }^{4,5}$ The $\mathrm{Cu} / \mathrm{PBI}$ coil was irradiated by electron beam to $120 \mathrm{MGy}$ and insulation voltage was tested. The insulation potential was held at $4.4 \mathrm{kV}$, and observed no cracks on the surface when the coil was wound to the self-diameter. For comparison poly(imide) $\left(\right.$ Kapton $^{\circledR}$ ) was tested, the potential voltage was $2.5 \mathrm{kV}$ after $60 \mathrm{MGy}$ irradiation by electron beam.

\section{Poly(arylate) (VECRUS ${ }^{\circledR}, V$ ECTRA $\left.{ }^{\circledR}\right)$}

VECRUS $^{\circledR}$ and VECTRA ${ }^{\circledR}$ are liquid crystal polymers. The polymers are high tensile strength, high flexural modulus, and high thermal resistance. Radiation resistance of VECTRA ${ }^{\circledR}$ (2-mm-thick-sheet) was tested by electron beam irradiation, and potential voltage of $34 \mathrm{kV}$ (initial value $53 \mathrm{kV}$ ) was held after $100 \mathrm{MGy}$ irradiation. For thin sheet processing, VECRUS $^{\circledR}$ was applied, and the radiation resistance was almost the same as VECTRA ${ }^{\circledR}$.

A VECRUS ${ }^{\circledR}$ thin sheet $(\mathrm{HC}-300 \mathrm{~A}, 300 \mu \mathrm{m})$ was coated with silicon polymer of $10-\mu \mathrm{m}$-thick layer. The silicon polymer was aromatic type, and Aluminum micro-flakes were dispersed into the silicon polymer by $10 \mathrm{wt} \%$. Al flake is atomized Aluminum powder produced by Toyo Aluminum K.K., and cover-coated by polymer, and has the following specifications, ALPASTE ${ }^{\circledR}$, atomized type D; $0.2 \mu \mathrm{m}$ thickness, $10-20 \mu \mathrm{m}$ size, specific surface area $8 \mathrm{~m}^{2} /$ $\mathrm{g}$, and the crystal structure of a face-centered cubic lattice.

Figure 1 shows scanning electron micrographs of

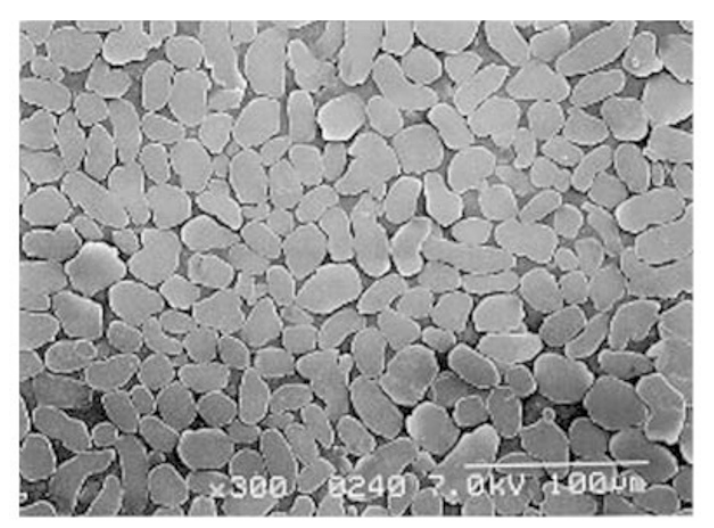

a

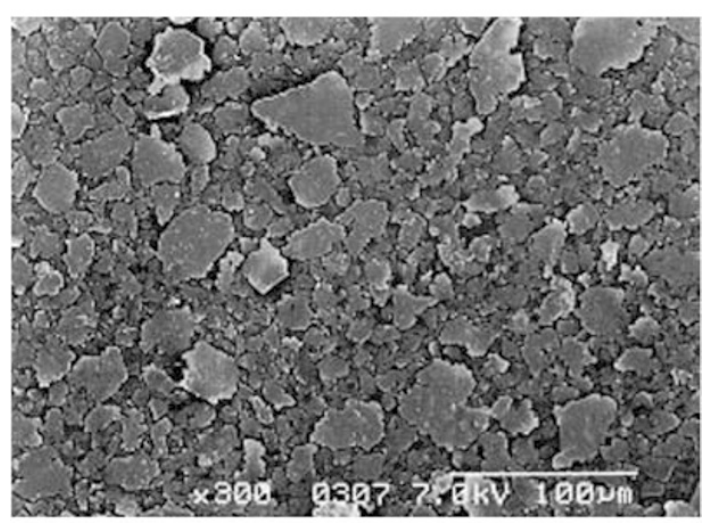

b

Figure 1. Scanning electron micrographs of $\operatorname{ALPASTE}^{\circledR}$ : (a) ALPASTE $^{\circledR}$ : (b) Conventional atomized-type aluminum powder leaf. 
Table I. Radiation resistance of VECRUS ${ }^{\circledR}$ coated by silicon polymer containing Al micro-flakes

\begin{tabular}{cccc}
\hline \multirow{2}{*}{ EB dose } & \multicolumn{3}{c}{ Break down voltage $(\mathrm{kV})$} \\
\cline { 2 - 4 } & Max & Mid & Min \\
\hline 0 (original) & 8.0 & 6.3 & 1.3 \\
20 MGy & 7.8 & 5.8 & 6.1 \\
50 MGy & 6.7 & 6.6 & 6.0 \\
100 MGy & 9.6 & 7.3 & 6.0 \\
\hline
\end{tabular}

ALPASTE $^{\circledR}$ compared with the conventional atomized-type aluminum powder leaf. ALPASTE ${ }^{\circledR}$ has uniform particle size, smooth flat surface and rounded edge easy to stack and leaf in a medium for paintcoating. ALPASTE ${ }^{\circledR}$ having these stacking and leafing properties should be superior to other with sunshine shield and radiation-durability owing to the Labyrinth Effect.

Radiation resistance of the coated VECRUS ${ }^{\circledR}$ was tested by break-down voltage after electron beam irradiation, and the results are listed in Table I. Coated VECRUS $^{\circledR}$ has high radiation resistance and the $\mathrm{Al}$ flakes improved the break down voltage at $100 \mathrm{MGy}$.

\section{Poly(phenyl-ether/urea) Grease}

Poly(phenyl-ether), a base polymer of lubricant, is an excellent polymer for a high radiation environment, and a mixture with urea was developed for high radiation resistant grease. ${ }^{6} \mathrm{Al}$ micro-flakes were mixed with the grease by $3-10 \mathrm{wt} \%$, and effect on the degradation of the grease was tested by $\gamma$-ray irradiation. The viscosity of the base polymer extracted from the grease was monitored in order to know the degree of radiation degradation at room temperature, and the observed values are listed in Table II with a reference of the grease without $\mathrm{Al}$ micro-flake.

Change in viscosity seems to be scattered, because the value increases with further polymerization of the base polymer and decreases with degradation of the base polymer, and the separation of urea may influence. From the observation of appearance, the radiation resistance of grease was improved by mixing $\mathrm{Al}$ flakes, that is, the grease structure was well main- tained after $100 \mathrm{MGy}$ irradiations, whereas the grease changed to fluid above around $60 \mathrm{MGy}$ without $\mathrm{Al}$ flakes because of degradation of urea as gelling agent.

\section{MOTOR FABRICATION}

\section{Specifications of Motor}

The motor is an induction motor (FORM, TISNNR) with four poles for three phase AC $200 \mathrm{~V}$, $0.75 \mathrm{~kW}$, and $1420 \mathrm{rpm}$ for $50 \mathrm{~Hz}$. Dimensions: $10 \mathrm{~cm}$ length and $10 \mathrm{~cm}$ diameter.

\section{Components of Motor and Fabrication}

The motor was made from the components with high-radiation resistant organic insulation materials. For coil wire, PBI was applied as described in the previous section. For insulation paper among coil wires, VECRUS $^{\circledR}$ paper which is non-woven fiber and coated with silicon polymer containing Al flaks was used. Of course, silicon polymer penetrates into the porous VECRUS $^{\circledR}$ paper. VECTRA ${ }^{\circledR}$ sheet was used for insulation board. The grease of poly(phenyl-ether/urea) mixed with $\mathrm{Al}$ flakes was used as the lubricant for ball bearings.

The other metal components and materials were the same as the conventional motor. Three motors were made by Meidensha Corporation using a commercial processing line and the motor after $100 \mathrm{MGy}$ radiation test is shown in Figure 2.

\section{Radiation Resistant of Test Motor}

The performance tests of the motor were made as follows.

(a) No-load test (Voltage, Current, Loss):

Characteristics test under no load showed a current $2.33 \mathrm{~A}$ (initial $2.32 \mathrm{~A}$ ) at $200 \mathrm{~V}$ and $50 \mathrm{~Hz}$. With locked-rotor test, primary resistance per phase at $115^{\circ} \mathrm{C}$, secondary induced voltage at standstill, all the other characteristics passed the specification by Meidensha Corp.

(b) Locked-rotor test:

Performance characteristics, such as current, efficiency, power factor, slip, maximum output,

Table II. Viscosity of grease and appearance after $\gamma$-ray irradiation at $100 \mathrm{MGy}$ for poly(phenyl-ether/urea) grease containing $\mathrm{Al}$ micro-flakes and without $\mathrm{Al}$ micro-flakes

\begin{tabular}{cccccc}
\hline $\begin{array}{c}\gamma \text {-ray dose } \\
(\text { MGy })\end{array}$ & \multicolumn{2}{c}{ Grease with Al flake } & & \multicolumn{2}{c}{ Grease without Al flake } \\
\cline { 2 - 3 } \cline { 5 - 6 } & Viscosity $\left(\mathrm{cm}^{2} / \mathrm{s}\right)$ & Appearance & & Viscosity $\left(\mathrm{cm}^{2} / \mathrm{s}\right)$ & Appearance \\
\hline 0 (original) & 1.3 & grease & & 1.3 & grease \\
20 & 1.6 & grease & & 1.7 & grease \\
40 & 1.6 & grease & & 1.8 & grease \\
60 & 1.4 & grease & & 1.7 & grease \\
80 & 1.6 & grease & & 1.6 & fluid \\
100 & 1.7 & grease & & 1.6 & fluid \\
\hline
\end{tabular}




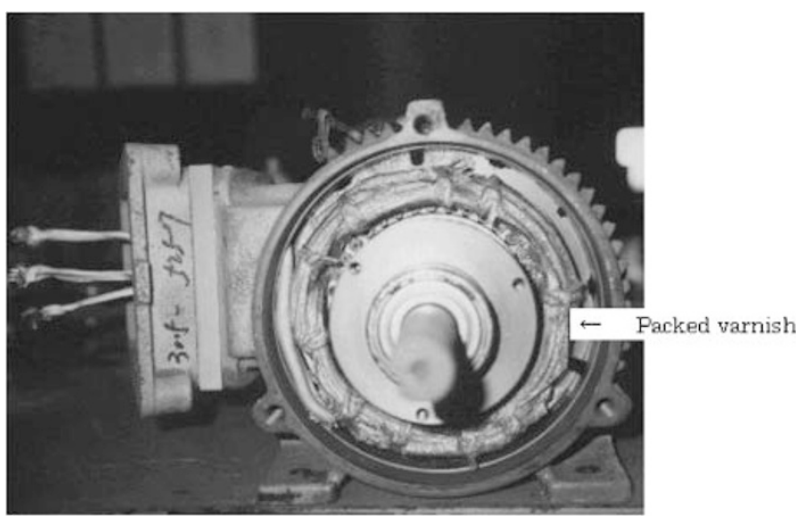

Figure 2. Prototype motor after $100 \mathrm{MGy}$ radiation test.

breakdown torque, starting current, and starting torque, were obtained from the so-called circle diagrams. All measurements showed normal values without changing from initial values. Surprisingly, the slip characteristic showed low values such as $1.06 \%$ (initially $1.20 \%$ ) at $25 \%$ load, $2.24 \%$ (initially $2.40 \%$ ) at $50 \%$ load, $3.58 \%$ (initially $3.90 \%$ ) at $75 \%$ load, $5.15 \%$ (initially $5.60 \%$ ) at $100 \%$ load, and $7.07 \%$ (initially $7.80 \%$ ) at $125 \%$ load because of a decrease of loss on hysteresis which mean an improvement of its insulation composition for the stator core of motor. Of course, the improvement of its insulation must owe to $\mathrm{Al}$ flake action.

(c) Irradiation of the motor was carried out by ${ }^{60} \mathrm{Co}$ $\gamma$-rays at room temperature at $10 \mathrm{kGy} / \mathrm{h}$. During irradiation, the motor was running with no-load. Electric current and leak current were monitored during irradiation, and after irradiation at $100 \mathrm{MGy}$, various properties were examined.

\section{RADIATION RESISTANCE OF DEVELOPED MOTOR}

The prototype motors (three pieces) were exposed to $\gamma$-rays with no-load. Electric current and leak current were monitored during irradiation. Both currents were almost constant. The electric current was $2.3 \mathrm{~A}$ and leak current at $1.3 \mathrm{~mA}$ after $100 \mathrm{MGy}$. Characteristics are shown in Table III for the original motor and 100 MGy irradiated motor. Values scarcely changed after $100 \mathrm{MGy}$ irradiations, although the insulation polymers were colored dark brown as shown in Figure 2. The motor was confirmed to operate without any problems to $\gamma$-rays irradiation after $100 \mathrm{MGy}$. The radiation endurance should be over $100 \mathrm{MGy}$. This is 50 times that of an ordinary radiation resistant motor of $2 \mathrm{MGy}$ at a nuclear power station.

\section{MECHANISM OF RADIATION IMPROVEMENT OF POLYMERS BY AL FLAKE}

The prototype motors (three pieces) were exposed to $\gamma$-rays with no-load. Electric current and leak current were monitored during irradiation. Both currents were almost constant. The electric current was $2.3 \mathrm{~A}$ and leak current at $1.3 \mathrm{~mA}$ after $100 \mathrm{MGy}$.

Characteristics are shown in Table III for the original motor and $100 \mathrm{MGy}$ irradiated motor. Values scarcely changed after 100 MGy irradiations, although the insulation polymers were colored dark brown as shown in Figure 2. The motor was confirmed to operate without any problems to $\gamma$-rays irradiation after 100 MGy. The radiation endurance should be over $100 \mathrm{MGy}$. This is 50 times that of an ordinary radia-

Table III. Characteristics of motor by locked-rotor test before (origin or non-irradiated motor) and after irradiation at $100 \mathrm{MGy}$. Electric power: AC $50 \mathrm{~Hz}, 200 \mathrm{~V}$

\begin{tabular}{|c|c|c|c|c|c|c|c|c|}
\hline \multirow{2}{*}{$\begin{array}{c}\text { Load } \\
(\%)\end{array}$} & \multicolumn{2}{|c|}{ Current (A) } & \multicolumn{2}{|c|}{ Efficiency $(\%)$} & \multicolumn{2}{|c|}{ Power $(\%)$} & \multicolumn{2}{|c|}{ Slip (\%) } \\
\hline & 100 MGy & Origin & 100 MGy & Origin & $100 \mathrm{MGy}$ & Origin & $100 \mathrm{MGy}$ & Origin \\
\hline 25 & 2.50 & 2.49 & 57.1 & 57.6 & 37.9 & 37.8 & 1.1 & 1.2 \\
\hline 50 & 2.82 & 2.81 & 70.2 & 70.5 & 54.7 & 54.7 & 2.2 & 2.4 \\
\hline 75 & 3.28 & 3.28 & 74.4 & 74.5 & 66.5 & 66.6 & 3.6 & 3.9 \\
\hline 100 & 3.88 & 3.88 & 75.0 & 74.9 & 74.3 & 74.4 & 5.2 & 5.6 \\
\hline 125 & 4.64 & 4.65 & 73.6 & 73.2 & 79.2 & 79.4 & 7.1 & 7.8 \\
\hline 150 & 5.61 & 5.66 & 70.5 & 69.7 & 82.2 & 82.4 & 9.6 & 10.7 \\
\hline \multirow{2}{*}{ Max output } & 100 MGy & Origin & & & & & & \\
\hline & $187 \%$ & $183 \%$ & & & & & & \\
\hline $\begin{array}{l}\text { Breakdown } \\
\text { torque }\end{array}$ & $237 \%$ & $237 \%$ & & & & & & \\
\hline $\begin{array}{c}\text { Starting } \\
\text { current }\end{array}$ & $17.4 \mathrm{~A}$ & $17.1 \mathrm{~A}$ & & & & & & \\
\hline $\begin{array}{c}\text { Starting } \\
\text { torque }\end{array}$ & $218 \%$ & $216 \%$ & & & & & & \\
\hline
\end{tabular}


tion resistant motor of $2 \mathrm{MGy}$ at a nuclear power station.

\section{MECHANISM OF RADIATION IMPROVEMENT OF POLYMERS BY AL FLAKE}

Al flakes mixed in polymer improved radiation resistance for VECRUS ${ }^{\circledR}$ and for grease by twice or more. This phenomenon was found out in our research and led to success. Al has high electric conductivity, but the polymers mixed with $\mathrm{Al}$ flakes in this paper have enough electric resistance the same as the original polymer. Carbon is a conductive material, but carbon particles such as carbon black mixed to polymers is applied to insulation. In the case of Al flakes, the effect of insulation for polymers may be the same as in the case of carbon particles. For polymers mixed with carbon particles, radiation resistance sometimes improve, but the improvement is small, so this effect has not been discussed.

As seen in Table I, VECRUS ${ }^{\circledR}$ sheet coated by silicon polymer containing $\mathrm{Al}$ micro-flakes greatly improve radiation resistance. To find the role of $\mathrm{Al}$ flakes in the polymer matrix, shielding effects of $\gamma$-rays through the polymer containing $\mathrm{Al}$ flakes were investigated. The sample was a VECRUS ${ }^{\circledR}$ sheet of $300 \mu \mathrm{m}$ thick and $10 \mathrm{~cm}$ square and overall thickness was $3.1 \mathrm{~mm}$. The stacked sheet was arranged in a $\gamma$-ray irradiation room as shown in Figure 3, and the $\gamma$-ray passed through the stacked sheet at different incident angles $\theta$ between the directions of incident $\gamma$-ray and the normal of the stacked sheets was monitored using a radiation detector (small size ionizing chamber: diameter $1.0 \mathrm{~cm}$, gas volume $0.3 \mathrm{~cm}^{3}$ ).

The intensity of $\gamma$-rays through shield material decreased according to eq 1 .

$$
I=I_{0} \exp (-\mu x)
$$

where $I_{0}$ incident intensity, $\mu\left(\mathrm{cm}^{-1}\right)$ linear attenuation coefficient, and $x(\mathrm{~cm})$ distance of penetration through shield material. When the shield material (VECRUS ${ }^{\circledR}$ sheet) is arranged with increasing $\theta$ between the direction of $\gamma$-ray and the material as shown

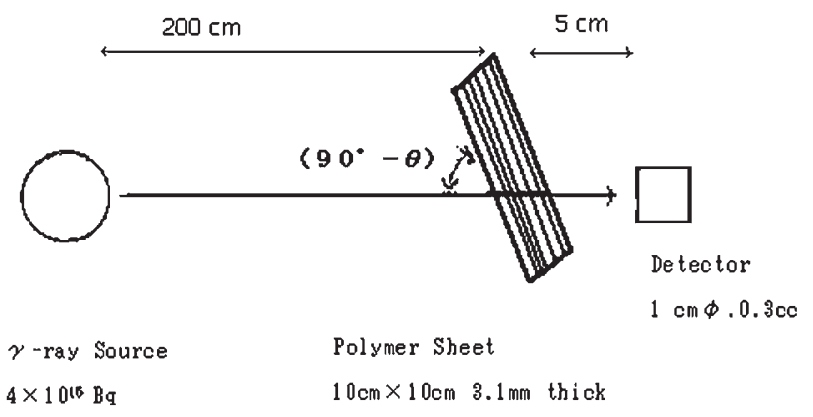

Figure 3. Arrangement for $\gamma$-ray shielding measurement.
Table IV. Dependency of incident angle $\theta$ on $\gamma$-rays shield by VECRUS $^{\circledR}$ sheet coated with silicon polymer including Al microflakes. 10 VECRUS $^{\circledR}$ sheets were stacked for measurement.

\begin{tabular}{|c|c|c|c|c|}
\hline \multirow{2}{*}{$\begin{array}{l}\text { Incident } \\
\text { angle } \theta \\
(\mathrm{deg})\end{array}$} & \multirow{2}{*}{$\begin{array}{l}\gamma \text {-ray } \\
\text { shield } \\
(\%)\end{array}$} & \multirow{2}{*}{$\begin{array}{l}\text { Attenuation } \\
\text { coefficient } \mu \\
\left(\mathrm{cm}^{-1}\right)\end{array}$} & \multicolumn{2}{|c|}{ Relative shield } \\
\hline & & & Observed & eq 2 \\
\hline 0 & 1.10 & 0.0358 & 1.00 & 1.00 \\
\hline 30 & 1.29 & 0.0361 & 1.17 & 1.15 \\
\hline 45 & 1.75 & 0.0403 & 1.59 & 1.41 \\
\hline 60 & 2.55 & 0.0416 & 2.32 & 2.00 \\
\hline
\end{tabular}

in Figure 3, the distance is given with $x / \cos \theta$. The intensity loss ratio ( $\gamma$-ray shield) is expressed as,

$$
\begin{aligned}
\Delta I & =\left(I_{0}-I\right) / I_{0} \\
& =1-\exp (-\mu x / \cos \theta)
\end{aligned}
$$

The observed values of the $\gamma$-ray shield as a function of the incident angle $\theta$ are listed in Table IV. The attenuation coefficient $\mu\left(\mathrm{cm}^{-1}\right)$ derived from observed values and relative shield ratio are also presented.

The observed attenuation coefficient $\mu$ increased with incident angle $\theta$, and the relative shield was higher than that estimated from eq 2 . The relation between $\mu$ and $1 / \cos \theta$ was plotted in Figure 4, and expressed as.

$$
\mu\left(\mathrm{cm}^{-1}\right)=0.03+0.006 / \cos \theta
$$

This effect was induced by $\mathrm{Al}$ flakes mixed in silicon polymer coated on VECRUS ${ }^{\circledR}$. Al flakes in the polymer are $10 \mathrm{wt} \%$ and coated layer is $10 \mu \mathrm{m}$ for both side of around $300 \mu \mathrm{m}$ VECRUS $^{\circledR}$ sheet, so Al flakes content in overall polymer is only $0.7 \mathrm{wt} \%$. $\mathrm{Al}$ flakes $(0.2-\mu \mathrm{m}$ thin film) may be aligned in parallel to silicon layer as seen in Figure 5, and reflects $\gamma$-ray effectively. The major absorption of $\gamma$-ray is Compton Scattering in matrix to produce the energetic electrons, which induce chemical reactions of polymers to result in degradation. Al flakes may decrease ener-

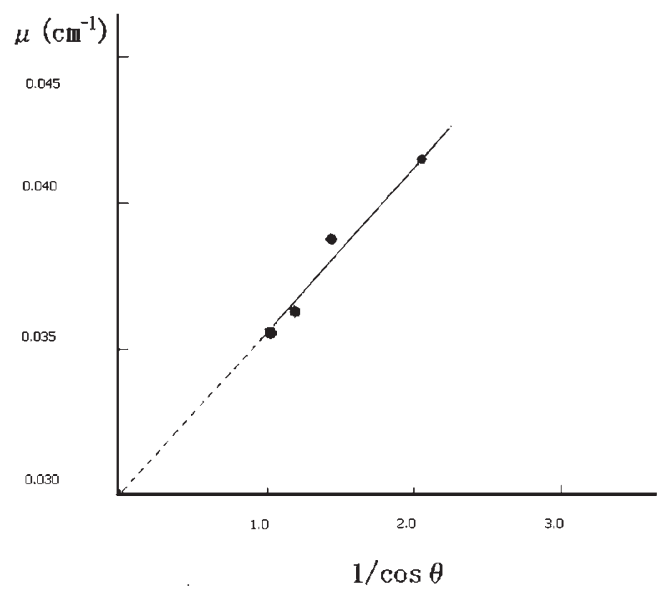

Figure 4. Relation between linear attenuation coefficient $\mu$ $\left(\mathrm{cm}^{-1}\right)$ and $1 / \cos \theta$ for VECRUS ${ }^{\circledR}$ sheet containing Al flake. 


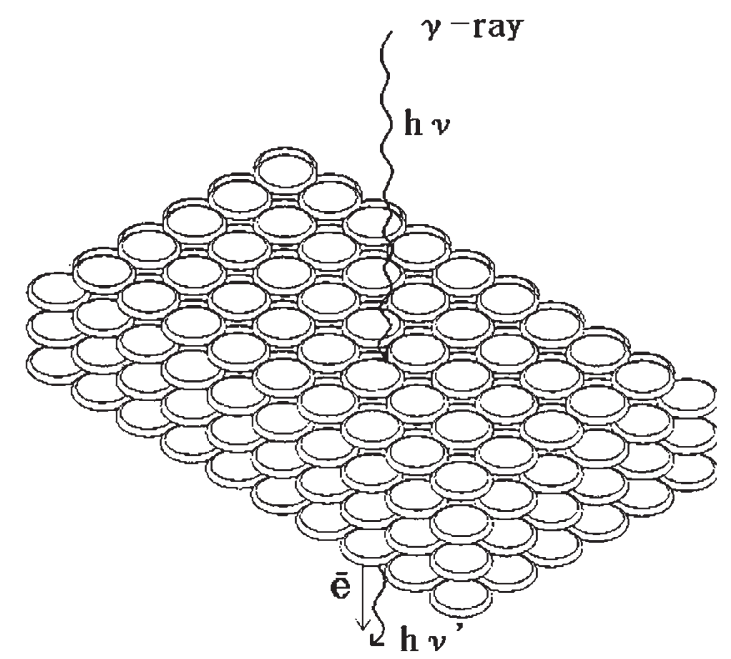

Figure 5. Schematic view of $\mathrm{Al}$ flakes in silicon layer on VECRUS $^{\circledR}$ and scattering of electrons.

gy of electrons in polymer matrix and reduce ionization of polymer chains.

\section{CONCLUSIONS}

A super radiation resistant motor of $100 \mathrm{MGy}$ was developed using endurable insulation polymers and mixing Al flake in the polymers. This motor could be applied to very sever radiation environment such as a nuclear fusion reactor. The conventional radiation resistant for motor so far used at practical nuclear power stations was of order of $2 \mathrm{MGy}$, so the prototype motor has 50 time higher radiation resistance.

Many polymers including the newly developed polymers were examined by $\gamma$-ray and electron beam irradiation at various environments and evaluated for the ITER components. The use of Al flakes showing the reduction of polymer degradation were the key point in this project and the processing technique as $\mathrm{Al}$ flake mixing into polymers or coating has been developed in the project. Components with enough radiation resistance were produced by the $\mathrm{R} \& \mathrm{D}$ group. $\mathrm{Al}$ flake action in radiation prevention is considered as the energy reduction of electron produced by $\gamma$-ray in the polymer matrix from the shield experiment. Although the shield was not so effective to decrease in radiation degradation, effective $\mathrm{Al}$ flake action in radiation prevention was found.

Acknowledgment. Authors express their gratitude to Dr. Tsuneo Sasuga, JAERI Takasaki, Japan for information on PBI radiation resistance, Dr. Takeshi Kunimi, Sumitomo Wiring Systems, Ltd., Suzuka, Japan for radiation shielding, Dr. Tasuku Nakai, Professor Emeritus of Hiroshima University, Hiroshima, Japan for $\gamma$-ray absorption to motor for $100 \mathrm{MGy}$ durability, and Mr. Makoto Noda, Sumitomo Corporation, Tokyo, Japan, Mr. Shinichi Sawamura, Mr. Saburou Tanaka, and Mr. Hideo Hata, Sumisho Plaschem Corp., Ltd., Osaka, Japan for coordination of the project.

\section{REFERENCES}

1. 382-1996 IEEE Standard for Qualification for Actuators for Power Operated Assemblies with Safety-Related Functions for Nuclear Power Plant.

2. T. Sato, Y. Ohkawa, T. Seguchi, T. Yagi, Y. Onishi, O. Murakami, Y. Murano, K. Funahashi, I. Ito, M. Miyamoto, and K. Mizude, Abstr. No.G-3 15th Annual Meeting of the Institute of Electrical Installation Engineers of Japan, "Planning an Insulator for Radiation Resistance and Characteristic Properties for Insulation,” Tokyo, Japan, Sep. 5, 1997.

3. T. Seguchi and Y. Morita, "Radiation Resistance of Plastics and Elastmers," in "Polymer Handbook VI," John Wiley \& Sons, Inc., Hoboken, NJ, 1999, pp 583-589.

4. Y. Onishi, A. Maeno, K. Iura, T. Ito, and K. Tsuji, Japan Patent Application HEI5-298942, 1993.

5. Y. Onishi, A. Maeno, K. Iura, T. Ito, M. Nagata, and T. Sasuga, Cryogenics, 35, 795 (1995).

6. K. Arakawa, H. Nakanishi, N. Morishita, T. Soda, N. Hayakawa, T. Yagi, and S. Machi, "Data on Radiation Resistance of Lubricating Oil,” JAERI-M 87-141, 1987. 